\title{
Evaluating Factors of Autistic Hiring through Ajzen's Theory of Planned Behavior: The HASSQAC Scale
}

\author{
Angela M. Mai \\ A. Victor Ferreros \\ Walden University \\ 100 S. Washington Ave. \#900 \\ Minneapolis, MN 55401 \\ United States
}

\begin{abstract}
This study assessed the construct validity of the Hiring Agent Survey regarding Selection of Qualified Autistic Candidates (HASSQAC) through factor and reliability analysis. Empirical evidence demonstrated the HASSQAC effectively measures Ajzen's theory of planned behavior regarding beliefs influencing hiring selection of autistics.KMO $=.831$ demonstrated factor analysis sample adequacy $(n=212)$. The Bartlett test for sphericity was significant $(p<.001)$. The first four factors explained $57 \%$ of the variance. A principal factor analysis with a forced 3 factor extraction using varimax orthogonal rotation constructed a clear conceptual picture of the relationships between items (factor loadings > .40). The 3 factors explained over $50 \%$ of the variance among the 45 items. Reliability analysis demonstrated significant Cronbach's alpha (control $=.923$; normative $=.846$; behavioral $=.901)$. Analysis of the 45-item scale demonstrated all but four factors were convergent with prior findings.
\end{abstract}

Keywords: HASSQAC; TPB, Employment, Beliefs, VABE, Influence, Autism, Disability

\section{Background}

The 2017 calculated unemployment rate for capable, qualified, working-age autistics was 83\% (Mai, 2018); which was a drastic contrast to the $4 \%$ unemployment rate for the rest of the United States (U.S. Department of Labor [DOL], 2017). Despite their keen desire to work (Anderson, McDonald, Edsall, Smith, \& Taylor, 2015; Hendricks, 2010; Wehmeyer, 2011), approximately four-million qualified, capable, autistic adults must rely on social services and dwell in extreme poverty conditions; thus, significantly taxing local, regional, and national economies (Cimera, 1996 - 2018; Council of State Administrators of Vocational Rehabilitation [CSAVR], 2011; Howlin, Alcock, \& Burkin, 2005; Standifer, 2012).Since 1957, decades of documented, supply-side, autistic employment research exist (Cimera, 2018;Unger, 2002) with dozens of scholars researching the topic in between. While a great deal of research from the supply-side (autistics, clinicians, and care-givers) abounds, the minimal existing demand-side (employers) study indicated employer belief as the key factor inhibiting employment (Mai, 2018; Scott et al., 2017; Stankova \& Trajkovski, 2010; Stuckey, 2016). Albeit, not only were Scott et al., Stankova and Trajkovski, and Stuckey's studies pursued from unrelated contexts, but they also contained limited demographic ranges and predictor similarities. Therefore, creating an effective instrument for uniformly measuring hiring agents' beliefs influencing their selection of qualified autistic candidates was critical in identifying potential interventions aimed at assisting those applicants gain competitive employment.

\section{The HASSQAC}

Development of the Hiring Agent Survey regarding Selection of Qualified Autistic Candidates (HASSQAC) included detailed literature examination, analysis of relevant instrumentation, and broad-scale peer review. Minimal literature referenced autistic demand-side influencers; thus, additional general disability literature inclusion inferred further predictor formation. While several instruments, identified in the literature, influenced HASSQAC construction, two existing instruments leant considerable validity, reliability, and design structure: Copeland, Chan,Bezyak, and Fraser's. (2010) version of the Affective Reactions subscale of Popovich, Scherbaum, Scherbaum, and Polinko's (2003) Disability Questionnaire andKaye, Jans, and Jones's (2011) 
Employer Questionnaire parts I \& II.Expert review provided final HASSQAC considerations before proceeding to a testing environment.

\subsection{Research and Theory}

Through in-depth review of employment-related autistic and general disability literature ranging from 1957 through 2017, a single common associated factor surfaced: Beliefs (Mai, 2018). Beginning with Unger's (2002) meta-analysis exploring employment-related autistic research from 1957 through 2000 and exhaustively reviewing literature through the end of 2017 (Hensel, 2017; Sarrett, 2017; Scott, 2017), Mai extrapolated 45 potential predictor variables. Through comprehensive theoretical analysis, Maiused Ajzen's (1985 - 2015) theory of planned behavior conceptually supported with five other solid belief-related social science theories (see Figure 1) to identify and categorize hiring agents' potential beliefs into three predictor dimensions (see Figure 2).

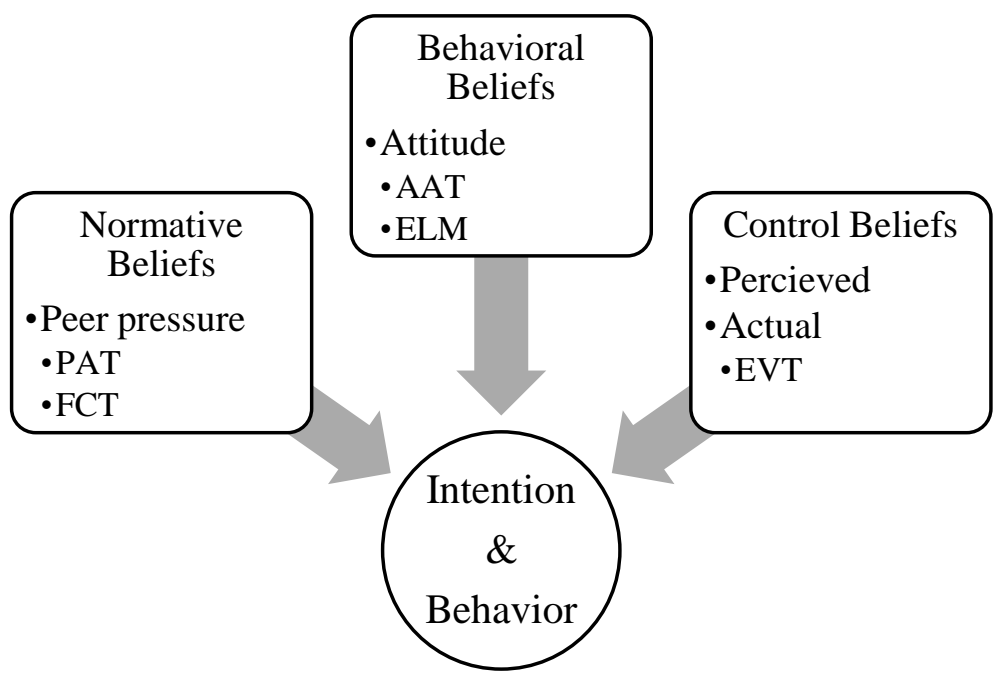

Figure 1. TPB and triangulating theories. Theoretical basis of the HASSQAC as constructed by Mai, A. M. (2018). Beliefs influencing hiring agents' selection of qualified autistic candidates (Doctoral dissertation). Retrieved from ProQuest Dissertations \& Thesis Global. (Order No 10751686).and adapted from "Theory of planned behavior" by Ajzen, I. (2004). In N. B. Anderson, Encyclopedia of Health and Behavior (pp. 709-712). Thousand Oaks, CA: SAGE Publications, Inc. doi:10.4135/9781412952576.n208

\begin{tabular}{|c|c|c|}
\hline Control & Normative & Behavioral \\
\hline $\begin{array}{c}\text { • Litigation } \\
\text { • Mediation } \\
\text { • Legislative understanding } \\
\text { - Accommodation costs } \\
\text { - Supported employment } \\
\text { • VR services } \\
\text { • Hiring costs } \\
\text { •Insurance costs } \\
\text { • Organizational - } \\
\text { • Goals } \\
\text { •Environment } \\
\text { - Committed resources } \\
\text { •Diversity plans } \\
\text { • Afinity plans } \\
\text { - Commitment to hire }\end{array}$ & 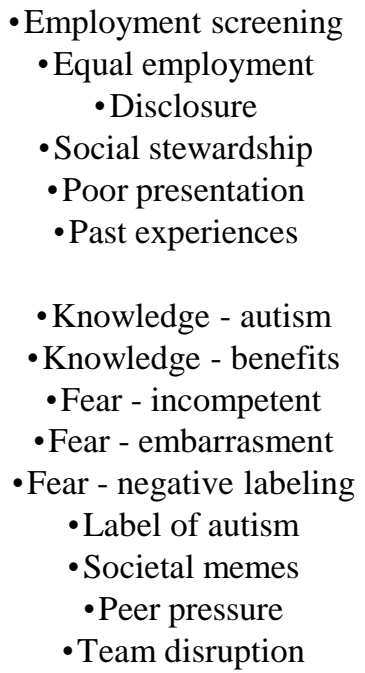 & $\begin{array}{c}\text { • Hard to supervise } \\
\text { - Absenteeism rates } \\
\text { • Adaptability } \\
\text { • Dedication } \\
\text { • Inconvenience } \\
\text { - Prefer physical disabilities } \\
\text { - Discrimination } \\
\text { • Stereotyping - } \\
\text { • Skills and ability } \\
\text { • Productivity } \\
\text { - Time and attention } \\
\text { • Problem employees } \\
\text {-Stereotypic movement } \\
\text { • Retardation } \\
\text { • Unreachable }\end{array}$ \\
\hline
\end{tabular}


Figure 2. HASSQAC independent (predictor) variables (control, normative, and behavioral beliefs) as classified by Mai, A. M. (2018). Beliefs influencing hiring agents' selection of qualified autistic candidates (Doctoral dissertation). Retrieved from ProQuest Dissertations \& Thesis Global. (Order No 10751686).

Expectancy-value theory (EVT; Fishbein, 1963) infers control beliefs influence behaviors. Pratkanis' (2000) altercasting theory (PAT) and Fay's (1987) critical theory (FCT) associate societal influences on normative beliefs. Ambivalence amplification theory (AAT; Katz, Wackenhut, \& Glass, 1979, 1986) and elaboration likelihood model of persuasion (ELM; Petty \& Cacioppo, 1979, 1986) equate personal beliefs and experiences to behavioral beliefs. Thus, Mai based HASSQAC variable inclusion (3 dimensions each containing 15 predictors) on extensive research and theory.

\subsection{Affective Reactions Subscale of the Disability Questionnaire}

The Affective Reactions subscale of Popovich et al.'s (2003) Disability Questionnaire addressed 22 reactionary items toward disabilities. The Disability Questionnaire contained three subscales with reliability ranging from $\alpha=$ .69 to $\alpha=.74$.Pillai's Trace $=.07, F(10,218)=0.801, p<.70, \eta 2=.035$ results indicate question order was nonsignificant; thus, question order did not affect scale reliability. In 2010, Copeland et al. further tested the Affective Reactions subscale using a larger participant sample and broader demographic range. Copeland et al. reported internal consistency of $\alpha=.69$ to $\alpha=.85$.Principle axis factor analysis $(21 \mathrm{x} 21)$ resulted in Kaiser-Meyer-Olkin $(K M O)=.82$ and Bartlett's test of sphericity $\chi^{2}(210, N=142)=1,081.03, p<.001$. The Kaiser-Guttman rule and Cattell's scree test indicated a three-factor solution. An oblique rotation accounted for $39 \%$ of the total variance presenting a parsimonious and good fit. Thus, Copeland et al. determined the Affective Reactions subscale measured three components of attitude. These findings indicated the design of the Affective Reactions subscale could effectively categorize control, normative, and behavioral beliefs as explained through concepts of TPB.

\subsection{Employer Questionnaire, parts I \& II}

The structure of the questions on Kaye et al.'s (2011) Employer Questionnaire were third person and nonincriminating. Kaye et al. inquired why employers thought other organizations did not employ disabled candidates and effectively circumvented legal-oriented preconceptions leading to predetermined and inaccurate answers. Such presentation worked well in accordance with EVT concepts that individuals act according to the expectations of their positions (Fishbein, 1963; Fishbein \& Ajzen, 1974;Magidson, Roberts, Collado-Rodriguez, 2014). While Kaye et al. did not provide statistics related to their instrument reliability as did Copeland et al. (2010), the base content of Kaye et al.'s survey tool was echoed in several other scholars' questionnaires. Thus, triangulation with those sources provided validation for structuring HASSQAC questions is a similar format.

\subsection{Peer Review}

After HASSQAC construction, a panel of 13 experts in associated fields reviewed and critiqued the instrument. Professional fields included advocacy (pertaining to autism and disability), business, public policy, human resources, medical (pertaining to autism), psychological (pertaining to autism), and vocational rehabilitation (pertaining to autism and disability).Feedback addressed a wide topic range from terminology and grammatical to medical and professional considerations. After editing, the same panel provided endorsement of the HASSQAC tool. Mai (2018) administered the HASSQAC in a survey to a sample of 212hiring agents.

\subsection{Initial Testing Environment}

A statistically significant $\left(F(45,73)=36.067, p<.001\right.$, adj. $\left.R^{2}=.930\right)$ multiple regression analysis $(n=$ 212)employed the HASSQAC scale testing hiring agents' beliefs (all three domains of TPB) influencing their selection of qualified autistic candidates (Mai, 2018).Mai further tested each TPB domain individually with statistically significant results: Control- $\left(F(15,107)=20.688, p<.001\right.$, adj. $\left.R^{2}=.708\right)$, normative- $(F(15,106)=$ $34.686, p<.001$, adj. $\left.R^{2}=.807\right)$, and behavioral- $\left(F(15,109)=11.066, p<.001\right.$, adj. $\left.R^{2}=.549\right)$. Variations in results due to isolating dimensions added support to Ajzen's TPB assumption that the combination of all three dimensions effectively predicts intent to act. Validity and reliability statistics of Mai's study demonstrated the efficacy of the HASSQAC scale in measuring beliefs influencing selection.

\section{Analysis}

The current study used factor analysis and reliability analysis to test the construct validity of the HASSQAC scale for measuring components of TPB regarding hiring agents' beliefs influencing their selection of qualified autistic candidates. Review of the factor analysis, scree plots, forced 3-factor solution, rotated factor matrix, and 
reliability analysis demonstrated significant empirical evidence that the HASSQAC effectively measures the three dimensions of Ajzen's theory of planned behavior regarding beliefs influencing selection of autistics.

\subsection{Factor Analysis}

The 45 items of the scale were intercorrelated. Initially a factor analysis included no forced extraction. The KMO measure of sampling adequacy was .831 indicating that the sample of 212 was adequate for factor analysis. The Bartlett test for sphericity was significant $(\mathrm{p}<.001)$. The Cattell scree plot for the full factor analysis demonstrated three key factors (see Figure 3).

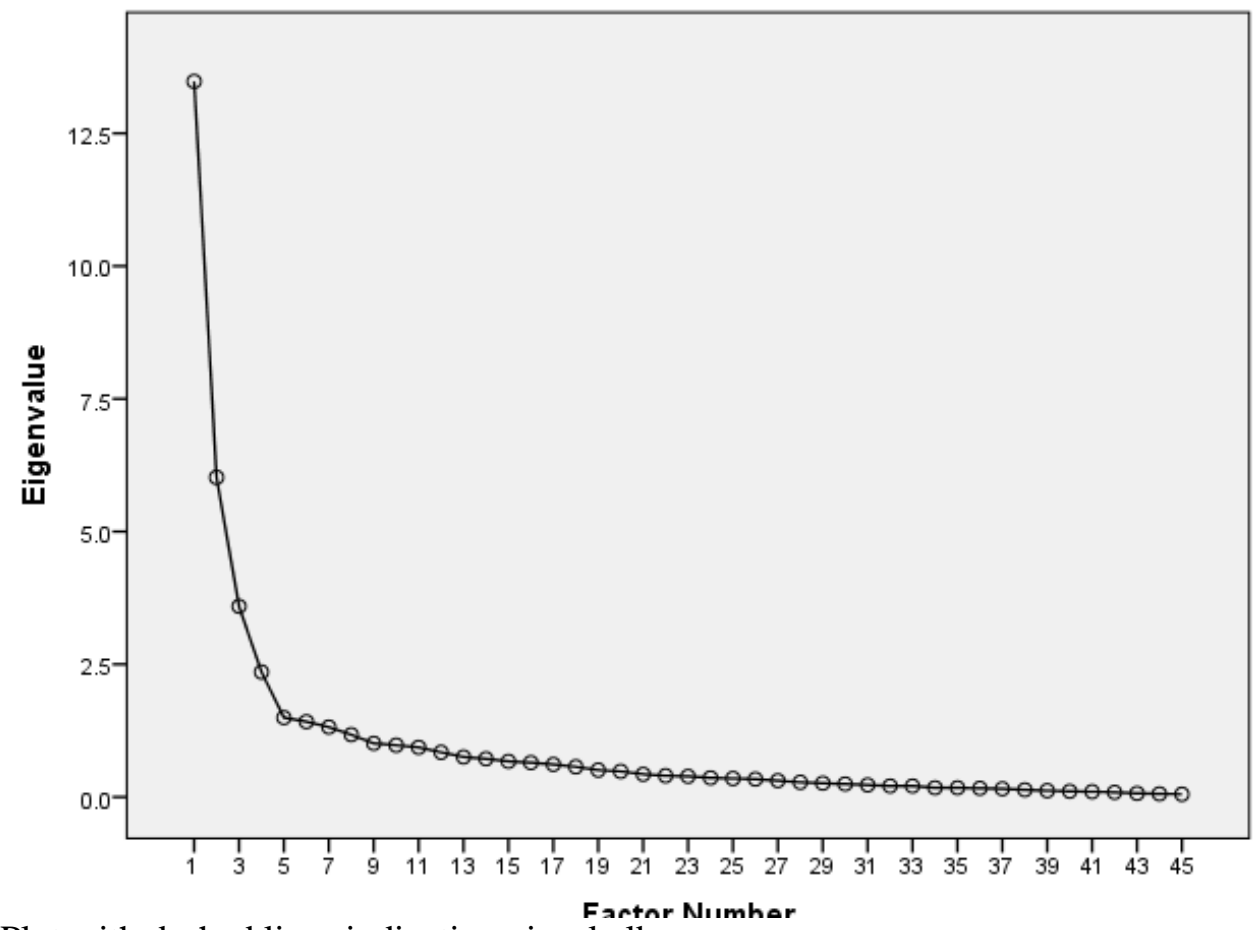

Figure 3. Scree Plot with dashed lines indicating visual elbow.

Cattell's scree plot reflected a distinct elbow demonstrating the "scree" after the first four factors. The first four factors explained $57 \%$ of the variance. Based on the latent variables in the underlying theory, a 3-factor extraction constructed a clear conceptual picture of the relationships between the items.

\subsection{Forced 3 factor Solution}

Table 1 shows the results of the principal factor analysis with a forced 3 factor extraction using varimax orthogonal rotation. The 3 factors explained over $50 \%$ of the variance among the 45 items.Considering factor loadings above .40 , patterns indicated three distinct factors.

2.2.1.VABEs. By looking at the content of the items, the nature of the variables each factor representedwas discernable. Clearly, all three TPB dimensions (control, normative, and behavioral) closely interacted with each other to predict intent to act. The balanced control, normative, and behavioral predictors (control $=13$, normative $=11$, behavioral $=12$ ) were easily apparent in the values, attitudes, beliefs, and expectations (VABEs) column providing significant support to the TPB framework referred to in Figure 1. This spread also supported Mai's (2018) multiple regression findings indicating a slightly stronger control slope $(B=.266)$ followed by a behavioral slope $(B=.195)$ and normative slope $(B=.187)$. Interestingly, this rotated 3 -factor matrix additionally identified separate factors hiring agents believe extend from demand-and supply-side contributors.

2.2.2. Demand-and supply-side factors. The 13 items above .40 in the demand column very specifically relate to organizational-level mandates and interpretations. Organizational leaders dictate items such as commitment to hire, goals and strategies, resources, diversity and affinity, costs, and screening processes. Whereas, organizations may differently interpret functions and mandates of legislature, equal employment law, and vocational rehabilitation services like supported employment and mediation. 
Nonetheless, hiring agents may see limitations to their role in initiating these demand-side factors leaving such influencers to organizational leaders. Additionally, hiring agents may believe the autistic candidate is the primary influencer of the six items in the supply column.

\subsection{Reliability Analysis}

Alpha reliability coefficients further demonstrated reliability of the HASSQAC. Exploring reliability relative to TPB dimensions and supply and demand factor variations added additional reliability confidence. Thus, the two separate approaches provided a more holistic interpretation.

2.3.1. TPB dimensions. Cronbach's alpha indicated significantly high reliability in all three dimensions (control $=.923$; normative $=.846$; behavioral $=.901)$.

\section{Table 1Rotated Factor Matrix}

\begin{tabular}{|c|c|c|c|}
\hline Belief and associated TPB dimension tested & $\begin{array}{l}\text { Factor } \\
\text { VABEs }\end{array}$ & Demand & Supply \\
\hline Q1 (c) Organizational commitment to hire. & .500 & .482 & -.209 \\
\hline Q2 (c) Organizational goals and strategies. & .494 & .546 & -.215 \\
\hline Q3 (c) Committed organizational resources. & .393 & .474 & -.133 \\
\hline Q4 (c) Legislative understanding. & .522 & .573 & -.079 \\
\hline Q5 (c) Organizational affinity group. & .545 & .480 & -.197 \\
\hline Q6 (c) Litigation. & .512 & .436 & -.165 \\
\hline Q7 (c) Organizational diversity plan. & .559 & .544 & -.151 \\
\hline Q8 (c) External mediation. & .494 & .460 & -.072 \\
\hline Q9 (c) Legal understanding. & .274 & .350 & -.015 \\
\hline Q10 (c) Insurance costs. & .539 & .443 & -.223 \\
\hline Q11 (c) VR services. & .563 & .473 & -.169 \\
\hline Q12 (c) Supported employment. & .567 & .468 & -.213 \\
\hline Q13 (c) Accommodation costs. & .505 & .468 & -.067 \\
\hline Q14 (n) Employment screening processes. & .577 & .429 & -.108 \\
\hline Q15 (n) Autism awareness. & .271 & .194 & .194 \\
\hline Q16 (n) Interview presentation. & .271 & .152 & .626 \\
\hline Q17 (n) Workplace contribution / benefits. & .321 & .292 & .699 \\
\hline Q18 (b) Stereotyping - Retardation. & .408 & .092 & .659 \\
\hline Q19 (b) Stereotyping - Skills and ability. & .390 & .185 & .691 \\
\hline Q20 (n) Hiring agent incompetence. & .412 & .323 & .465 \\
\hline Q21 (n) Disclosure. & .396 & .269 & .477 \\
\hline Q22 (n) Societal pressure. & .501 & -.294 & -.020 \\
\hline Q23 (n) Negative team performance impact. & .523 & -.324 & -.006 \\
\hline Q24 (n) Coworker ostracization. & .555 & -.324 & .119 \\
\hline Q25 (n) Equal employment practices. & .572 & -.386 & .090 \\
\hline Q26 (n) Label of autism. & .644 & -.268 & .048 \\
\hline Q27 (n) Past experience with autistics. & .524 & -.327 & .141 \\
\hline Q28 (n) Coworker refusal of autistic direction. & .547 & -.360 & -.034 \\
\hline Q29 (b) Stereotyping - Productivity. & .561 & -.373 & .057 \\
\hline Q30 (n) Embarrassed by autistics. & .522 & -.252 & -.234 \\
\hline Q31 (c) Workplace environment. & .733 & -.201 & .151 \\
\hline Q32 (c) Hiring costs. & .721 & -.199 & -.031 \\
\hline Q33 (b) Adaptability. & .658 & -.240 & .184 \\
\hline Q34 (b) Hard to supervise. & .656 & -.247 & .059 \\
\hline Q35 (b) Stereotypical movement. & .686 & -.306 & .113 \\
\hline Q36 (b) Stereotyping - Time and attention. & .758 & -.317 & -.009 \\
\hline Q37 (b) Inconvenience. & .747 & -.389 & -.018 \\
\hline Q38 (b) Absenteeism rates. & .592 & -.272 & -.136 \\
\hline Q39 (b) Autistic job dedication. & .375 & -.196 & -.248 \\
\hline Q40 (b) Discrimination. & .496 & -.166 & -.294 \\
\hline Q41 (n) Social stewardship practices. & .591 & -.149 & -.200 \\
\hline Q42 (b) Stereotyping - Potential to learn. & .617 & -.167 & -.061 \\
\hline Q43 (b) Stereotyping - Problem employees. & .572 & -.329 & -.267 \\
\hline Q44 (b) Autistics cannot communicate. & .556 & -.263 & -.036 \\
\hline Q45 (b) Preference for physical disabilities. & .318 & -.337 & -.228 \\
\hline
\end{tabular}

Extraction Method: Principal Axis Factoring.

a. 3 factors extracted. 5 iterations required.

b. Control (c), normative (n), and behavioral (b) scale items.

Note. Factors $<.40$ bolded for pattern identification purposes. 
Table 2.Control Item-Total Statistics

\begin{tabular}{ll|lll} 
& $\begin{array}{l}\text { Scale Mean } \\
\text { if Item }\end{array}$ & $\begin{array}{l}\text { Cale Variance } \\
\text { Deleted }\end{array}$ & $\begin{array}{l}\text { Total } \\
\text { ifltem Deleted } \\
\text { Correlation }\end{array}$ & $\begin{array}{l}\text { Item-Cronbach's } \\
\text { Alpha if Item } \\
\text { Deleted }\end{array}$ \\
\hline Q1 (c) Organizational commitment to hire. & 70.89 & 148.162 & .713 & .915 \\
\hline Q2 (c) Organizational goals and strategies. & 70.55 & 149.376 & .726 & .915 \\
\hline Q3 (c) Committed organizational resources. & 70.41 & 154.196 & .603 & .919 \\
\hline Q4 (c) Legislative understanding. & 70.41 & 149.577 & .717 & .915 \\
\hline Q5 (c) Organizational affinity group. & 70.80 & 148.032 & .718 & .915 \\
\hline Q6 (c) Litigation. & 70.58 & 147.642 & .697 & .916 \\
\hline Q7 (c) Organizational diversity plan. & 70.49 & 144.030 & .765 & .913 \\
\hline Q8 (c) External mediation. & 70.70 & 150.767 & .650 & .917 \\
\hline Q9 (c) Legal understanding. & 70.78 & 156.872 & .395 & .926 \\
\hline Q10 (c) Insurance costs. & 70.71 & 149.684 & .707 & .916 \\
\hline Q11 (c) VR services. & 70.49 & 150.649 & .715 & .916 \\
\hline Q12 (c) Supported employment. & 70.28 & 146.550 & .737 & .914 \\
\hline Q13 (c) Accommodation costs. & 70.12 & 149.184 & .669 & .917 \\
\hline Q31 (c) Workplace environment. & 70.66 & 159.734 & .391 & .924 \\
\hline Q32 (c) Hiring costs. & 70.84 & 157.689 & .398 & .925
\end{tabular}

a. Control (c), normative (n), and behavioral (b) scale items.

Note. Factors wherein alphaincreases bolded for identification purposes.

Table 3.Normative Item-Total Statistics

\begin{tabular}{lllll} 
& $\begin{array}{l}\text { Scale Mean } \\
\text { if Item } \\
\text { Deleted }\end{array}$ & $\begin{array}{l}\text { Scale Variance } \\
\text { if Item Deleted }\end{array}$ & $\begin{array}{l}\text { Total } \\
\text { Correlation }\end{array}$ & $\begin{array}{l}\text { Alpha if Item } \\
\text { Deleted }\end{array}$ \\
\hline Q14 (n) Employment screening processes. & 68.52 & 88.235 & .344 & .846 \\
\hline Q15 (n) Autism awareness. & 69.11 & 90.181 & .297 & .848 \\
\hline Q16 (n) Interview presentation. & 67.81 & 92.253 & .337 & .844 \\
\hline Q17 (n) Workplace contribution / benefits. & 67.70 & 92.520 & .345 & .844 \\
\hline Q20 (n) Hiring agent incompetence. & 68.29 & 87.610 & .396 & .842 \\
\hline Q21 (n) Disclosure. & 68.02 & 89.629 & .366 & .843 \\
\hline Q22 (n) Societal pressure. & 68.74 & 86.293 & .482 & .837 \\
\hline Q23 (n) Negative team performance impact. & 68.85 & 81.775 & .606 & .829 \\
\hline Q24 (n) Coworker ostracization. & 68.56 & 83.748 & .653 & .827 \\
\hline Q25 (n) Equal employment practices. & 68.50 & 83.736 & .632 & .828 \\
\hline Q26 (n) Label of autism. & 68.62 & 81.753 & .712 & .823 \\
\hline Q27 (n) Past experience with autistics. & 68.73 & 83.877 & .594 & .830 \\
\hline Q28 (n) Coworker refusal of autistic direction. & 68.49 & 85.316 & .536 & .834 \\
\hline Q30 (n) Embarrassed by autistics. & 68.41 & 88.050 & .403 & .841 \\
\hline Q41 (n) Social stewardship practices. & 68.38 & 88.753 & .439 & .839 \\
\hline
\end{tabular}

a. $\quad$ Control (c), normative (n), and behavioral (b) scale items.

Note. Factors where in alpha increases bolded for identification purposes. 


\section{Table 4. Behavioral Item-Total Statistics}

\begin{tabular}{|c|c|c|c|c|}
\hline Belief and associated TPB dimension & $\begin{array}{l}\text { Scale Mean } \\
\text { if Item } \\
\text { Deleted }\end{array}$ & $\begin{array}{l}\text { Scale Variance if } \\
\text { Item Deleted }\end{array}$ & $\begin{array}{l}\text { Corrected } \\
\text { Item-Total } \\
\text { Correlation }\end{array}$ & $\begin{array}{l}\text { Cronbach's } \\
\text { Alpha if Item } \\
\text { Deleted }\end{array}$ \\
\hline Q18 (b) Stereotyping - Retardation. & 68.87 & 116.022 & .305 & .903 \\
\hline Q19 (b) Stereotyping - Skills and ability. & 68.63 & 116.848 & .257 & .904 \\
\hline Q29 (b) Stereotyping - Productivity. & 69.31 & 107.791 & .525 & .897 \\
\hline Q33 (b) Adaptability. & 69.38 & 105.907 & .681 & .891 \\
\hline Q34 (b) Hard to supervise. & 68.99 & 104.055 & .697 & .890 \\
\hline Q35 (b) Stereotypical movement. & 69.55 & 103.855 & .704 & .889 \\
\hline Q36 (b) Stereotyping - Time and attention. & 69.16 & 102.674 & .781 & .886 \\
\hline Q37 (b) Inconvenience. & 69.30 & 102.840 & .757 & .887 \\
\hline Q38 (b) Absenteeism rates. & 69.67 & 103.939 & .672 & .891 \\
\hline Q39 (b) Autistic job dedication. & 70.24 & 108.374 & .445 & .901 \\
\hline Q40 (b) Discrimination. & 69.44 & 108.862 & .485 & .898 \\
\hline Q42 (b) Stereotyping - Potential to learn. & 69.10 & 107.698 & .667 & .892 \\
\hline Q43 (b) Stereotyping - Problem employees. & 69.53 & 104.487 & .658 & .891 \\
\hline Q44 (b) Autistics cannot communicate. & 68.84 & 109.345 & .635 & .893 \\
\hline Q45 (b) Preference for physical disabilities. & 69.91 & 109.771 & .446 & .900 \\
\hline
\end{tabular}

a. Control (c), normative (n), and behavioral (b) scale items.

Note. Factors wherein alphaincreases bolded for identification purposes.

Tables 2, 3, and 4 showscale mean, variance, total correlation, and alpha variance of each item if deleted. Removal of three control-items would cause the overall alpha to increase slightly albeit reliability coefficients with all 15-items included were acceptable. Similarly, removing one normative-item and two behavioral items would cause slight overall alpha increases. The three control-items bringing down overall alpha each correlated to a factor that hiring agents believe have less influence than the other control-items. Interpretation inferred that hiring agents are more confident of their legal understanding than their legislative understanding. Additionally, hiring agents may believe that hiring costs are either a minimal consideration or, more likely, a part of the larger organizational resource commitment. A similar inference was apparent when organizational goals, strategies, and diversity initiatives include workplace environment.

Throughout Mai's (2018) multiple regression and this factor reliability analysis, it was apparent that hiring agents are aware of autism. That awareness might explain why removal of question 15 increased alpha levels. However, since that increase was minimal (.002) hiring agents may not feel their autism awareness is high enough to perform their jobs or hire qualified autistic candidates. Given other normative factors' alpha scores, societal memes were clearly influencing how hiring agents perform their job responsibilities. Since removal of behavioral stereotyping retardation and skills and ability factors would increase overall alpha, there was indication that hiring agents' VABEs are moving away from archaic autism caricatures to a more comprehensive understanding. Nonetheless, the high alpha scores of all the behavioral dimension items clearly inferred hiring agents' behavioral beliefs influence their selection. Additionally, the balance of all three dimensions not only supported the foundation of TPB but also provided indication of why the forced 3-factor analysis did not separate items based on TPB dimensions and, instead, separated factors based on VABES, demand- and supply-side influencers.

2.3.2. VABES, supply and demand. As Ajzen (1985, 2004, 2011, 2015) pointed out, TPB incorporates dimensions of control, normative, and behavioral beliefs to indicate intent to act.

Thus, TPB is an effective theory for predicting action. This same assumption infers that each dimension cannot effectively separate from the other two without altering the final predictive element. Not only was this concept apparent in Mai's (2018) multiple regression study, it was evident in this reliability analysis. The three factors identified were not the three different dimensions of TPB, rather, they were the VABES that hiring agents felt they had a high degree of control over and those factors that where less within their ability to influence: primarily demand- and supply-side contributors (see Table 1).

While the VABEs column certainly contains aspects of supply and demand influencers, hiring agents' influence is strongly present. Whereas organizational leaders most strongly influence demand-side and qualified autistic candidates contribute more to supply-side factors. 
Also noted was that only one demand-side factor was not also significant within the VABEs column indicating that hiring agents recognize their substantial role in the demand-side factors. However, only two supply-side factors were also significant in the VABEs column: Retardation stereotyping and hiring agent incompetence. Given that retardation stereotyping is significantly stronger in the supply-side column, hiring agents believe that qualified autistic candidates are most responsible for overcoming that influencing belief. Similarly, the significance of hiring agent incompetence closely balances indicating that influence from both factors was significant. Interestingly, the demand-side column also indicated some influence of organizational leaders on hiring agent competence.

\section{Factorial Validity -Discussion}

Taking into consideration Mai's (2018) multiple regression study along with this reliability analysis of the HASSQAC, clear convergences were evident as well as some divergences. Mai noted that control, behavioral, and normative beliefs presented a balanced spread among the most significant items. This reliability analysis demonstrated the same progression of significance among the three dimensions.

Among a plethora of convergences, several stand out. Mai (2018) reported hiring agents most significantly believe organizations must include autistics in their diversity policies and practices. This 3 -factor forced solution confirmed Mai's finding demonstrating that some items with significantly high factor loadings were in both the VABEs and demand-side columns. Mai reported the second strongest influencer as stereotyping absenteeism and dependability which this reliability analysis also showed significant. Mai also noted the significant embarrassment of hiring agents when contemplating employment of qualified autistic candidates; a factor likewise significant in this analysis. Additionally, reliability analysis showed decreased alpha levels with removal of each of these items from the scale.In both studies, legal understanding, interview presentation, disclosure, and autistic job dedication were not among the most significant factors.

Four factors, two normative and two behavioral, were divergent in both studies. Mai (2018) reported hiring agents' autism awareness, autistics' workplace contributions, hiring agents' stereotyping of autistics' skills and abilities, and hiring agents' preference for physical disabilities among significant factors. Whereas, this reliability analysis reflected minimally significant factor loadings pertaining to those factors. Considering removal of autism awareness and stereotyping skills and ability also resulted in increased overall alpha scores, these two factors may warrant closer scrutiny. While autistics' workplace contributions did load significant in this analysis, this item reflected in the supply-side column. Thus, hiring agents do believe workplace contribution concerns are a significant influencer but feel the qualified autistic candidate controls this factor. Preference for physical disabilities presented the largest anomaly. With a low factor loading but a contributing alpha increase and high statistical significance in Mai's (2018) multiple regression, this factor needs further exploration before establishing factor reliability.

Overall, considering the size and depth of the HASSQAC scale, it represents a highly reliable and useful tool measuring hiring agent's beliefs influencing their intention to hire qualified autistic candidates. Empirical evidence demonstrated the HASSQAC effectively measures the three dimensions of Ajzen's TPB regarding beliefs influencing hiring selection of autistics. Future evaluation of the scale should include in-depth exploration of the four divergent factors, isolation of supply-side factors, and further analysis of strong demand-side factors among hiring agents' VABEs.

\section{References}

Ajzen, I. (1985). From intentions to actions: A theory of planned behavior. In J. Kuhl \& J. Beckman (Eds.), Actioncontrol: From cognition to behavior (pp. 11-39). Heidelberg, Germany: Springer.

Ajzen, I. (2004). Theory of planned behavior. In N. B. Anderson, Encyclopedia of health and behavior (pp. 709-712). Thousand Oaks, CA: SAGE Publications, Inc. doi:10.4135/9781412952576.n208

Ajzen, I. (2011). The theory of planned behavior: Reactions and reflections. Psychology \& Health, 26, 1113-1127. doi:10.1080/08870446.2011.613995

Ajzen, I. (2015). The theory of planned behavior is alive and well, and not ready to retire: A commentary on Sniehotta, Presseau, and Araújo-Soares. Health Psychology Review, 9, 131-137.

doi:10.1080/17437199.2014.883474 
Anderson, K. A., McDonald, T. A., Edsall, D., Smith, L. E., \& Taylor, J. L. (2015). Postsecondary expectations of high-school students with autism spectrum disorders. Focus on Autism and Other Developmental Disorders, 31, 16-26. doi:10.1177/1088357615610107

Cimera, R. E. (2000). The cost-efficiency of supported employment programs: A literature review. Journal of Vocational Rehabilitation, 14(1), 51-55. Retrieved from http://www.iospress.nl/journal/journal-of-vocationalrehabilitation

Cimera, R. E. (2002). The monetary benefits and costs of hiring supported employees: A primer. Journal of Vocational Rehabiliation, 17(1), 23-32. Retrieved from http://www.iospress.n1/journal/journal-of-vocational-rehabilitation

Cimera, R. E. (2006). The monetary benefits and costs of hiring supported employees: Revisited. Journal of Vocationa Rehabilitation, 24(3), 137-144. Retrieved from http://www.iospress.nl/journal/journal-of-vocationalrehabilitation

Cimera, R. E. (2007). The cumulative cost-effectiveness of supported and sheltered employees with mental retardation. Research \& Practice for Persons with Severe Disabilities, 32, 247-252. doi:10.2511/rpsd.32.4.247

Cimera, R. E. (2008). The cost-trends of supported employment versus sheltered employment. Journal of Vocational Rehabilitation, 28(1), 15-20. Retrieved from http://www.iospress.nl/journal/journal-of-vocationalrehabilitation

Cimera, R. E. (2009a). Supported employment's cost-efficiency to taxpayers: 2002 to 2007. Research and Practice for Persons with Severe Disabilities, 34, 13-20. doi:10.2511/rpsd.34.2.13

Cimera, R. E. (2009b). The national costs of supported employment to vocational rehabilitation: 2002 to 2006. Journal of Vocational Rehabilitation, 30(1), 1-9. Retrieved from http://www.iospress.nl/journal/journal-of-vocationalrehabilitation

Cimera, R. E. (2010). The national cost-efficiency of supported employees with intellectual disabilities: The worker's perspective. Journal of Vocational Rehabilitation, 33(2), 123-131. Retrieved from http://www.iospress.nl/journal/journal-of-vocational-rehabilitation

Cimera, R. E. (2011). Supported versus sheltered employment: Cumulative costs, hours worked, and wages earned. Journal of Vocational Rehabilitation, 35, 85-92. doi:10.3233/JVR-2011-0556

Cimera, R. E. (2012). The economics of supported employment: What new data tell us. Journal of Vocational Rehabilitation, 37(2), 109-117. Retrieved from http://www.iospress.nl/journal/journal-of-vocationalrehabilitation

Cimera, R. E. (2014). Reducing the cost of providing supported employment services: A preliminary study. Journal of Vocational Rehabilitation, 80(3), 4-10. Retrieved from http://www.iospress.nl/journal/journal-of-vocationalrehabilitation

Cimera, R. E., \& Burgess, S. (2011). Do adults with autism benefit monetarily from working in their communities? Journal of Vocational Rehabiltation, 34, 173-180. doi:10.3233/JVR-2011-0545

Cimera, R. E., \& Cowan, R. (2009). The costs of services and employment outcomes achieved by adults with autism in the US. Autism, 13, 285-302. doi:10.1177/1362361309103791

Cimera, R. E., \& Oswald, G. (2009). An exploration of the costs of services funded by Vocational Rehabilitation. Journal of Rehabilitation, 75(1), 18-26. Retrieved from http://www.iospress.nl/journal/journal-of-vocationalrehabilitation

Cimera, R. E., \& Rumrill, P. D. (2008). Economic analyses of rehabilitation services as research methodologies. Work, 31(4), 483-487. Retrieved from http://www.iospress.nl/journal/work

Cimera, R. E., Thoma, C. A., Whittenburg, H. N., \&Ruhl, A. N. (2018). Is getting postsecondary education a good investment for supported employees with intellectual disability and taxpayers? Is postsecondary education a good investment? Inclusion, 6, 97-109. doi:10.1352/2326-6988-6.2.97

Clawson, J. G. (2012). Level three leadership: Getting below the surface (5 $5^{\text {th }}$ ed.). Upper Saddle River, NJ: Pearson Educational.

Copeland, J., Chan, F., Bezyak, J., \& Fraser, R. (2010). Assessing cognitive and affective reactions of employers toward people with disabilities in the workplace. Journal of Occupational Rehabilitation, 20, 427-434. doi:10.1007/s10926-009-9207-y

Council of State Administrators of Vocational Rehabilitation [CSAVR], 2011

Fay, B. (1987). Critical social science: Liberation and its limits. Ithaca, NY: Cornell University Press.

Fishbein, M. (1963). An investigation of the relationships between beliefs about an object and the attitutude toward that object. Human Relations, 16, 233-239. doi:10.1177/001872676301600302

Fishbein, M., \& Ajzen, I. (1974). Attittudes toward objects as predictors of single and multiple behavioral criteria. Psychological Review, 81, 59-74. doi:10.1037/h0035872 
Hendricks, D. (2010). Employment and adults with autism specturm disorders: Challenges and strategies for success. Journal of Vocational Rehabilitation, 32, 125-134. doi:10.3233/JVR-2010-0502

Hensel, W. F. (2017). People with autism spectrum disorder in the workplace: An expanding legal frontier [Research Paper No. 2017-01]. Georgia State University College of Law, Legal Studies Harvard Civil Rights - Civil Liberties Law Review (CR - CL). Retrieved from https://papers.ssrn.com

Howlin, P., Alcock, J., \& Burkin, C. (2005). An 8 year follow-up of a specialist supported employment service for high-ability adults with autism or Asperger syndrome. Autism: The International Journal of Research \& Practice, 9, 533-549. doi:10.1177/1362361305057871

Katz, I., \& Glass, D. C. (1979). An ambivalence amplification theory of behavior toward the stigmatized. In W. Austin $\&$ S. Worchel (Eds.), The social psychology of intergroup relations (pp. 55-70). Monterrey, CA: Brooks/Cole.

Katz, I., Wackenhut, J., \& Glass, D. C. (1986). An ambivalence-amplification theory of behavior toward the stigmatized. In S. Worchel, \& W. G. Austin, Psychology of intergroup relations (pp. 103-117). Chicago, IL: Nelson-Hall.

Kaye, H. S., Jans, L. H., \& Jones, E. C. (2011). Why don't employers hire and retain workers with disabilities? Journal of Occupational Rehabilitation, 21, 526-536. doi:10.1007/s10926-011-9302-8

Kregal, J., Wehman, P., Revell, G., Hill, J., \& Cimera, R. E. (2000). Supported employment benefit-cost analysis: Preliminary findings. Journal of Vocational Rehabilitation, 14(3), 153-157. Retrieved from http://www.iospress.nl/journal/journal-of-vocational-rehabilitation

Magidson, J. F., Roberts, B. W., Collado-Rodriguez, A., \& Lejuez, C. W. (2014). Theory-driven intervention for changing personality: Expectancy-value theory, behavioral activation, and conscientiousness. Developmental Psychology, 50, 1442-1450. doi:10.1037/a0030583

Mai, A. M. (2018). Beliefs influencing hiring agents' selection of qualified autistic candidates (Doctoral dissertation). Retrieved from ProQuest Dissertations \& Thesis Global. (Order No 10751686).

Petty, R. E., \& Cacioppo, J. T. (1979). Issue involvement can increase or decrease persuasion by enhancing messagerelevant cognitive processes. Journal of Personality and Social Psychology, 37, 1915-1926. doi:10.1037/00223514.37.10.1915

Petty, R. E., \& Cacioppo, J. T. (1986). Communication and persuasion: Central and peripheral routes to attitude change. New York, NY: Springer-Verlag.

Popovich, P. M., Scherbaum, C. A., Scherbaum, K. L., \& Polinko, N. (2003). The assessment of attitudes toward individuals with disabilities in the workplace. The Journal of Psychology, 137, 163-177. doi:10.1080/00223980309600606

Pratkanis, A. R. (2000). Altercasting as an influence tactic. In D. J. Terry, \& M. A. Hagg, Attitudes, behavior and social context: The role of group norms and group membershp (pp. 201-226). Mahwah, NJ: Laurence Earlbaum Associates.

Rusch, F. R., \& Cimera, R. E. (1996). Employment and autism: An old frontier for new explorers. PsycCritiques, 41, 173. doi:10.1037/002728

Sarrett, J. (2017). Interviews, disclosures, and misperceptions: Autistic adults' perspectives on employment related challenges. Disability Studies Quarterly, 37(2). Retreived from http://dsq-sds.org

Scott, M., Jacob, A., Hendrie, D., Parsons, R., Girdler, S., Falkmer, T., Falkmer, M. (2017). Employers' perceptions of the costs and the benefits of hiring individuals with autism spectrum disorder in open employment in Australia. PLON One, 12. doi:10.1371/journal. pone.0177607

Standifer, S. W. (2012). Fact sheet on autism employment. National Conference on Autism \& Employment. St. Louis: MO. Autism Works. Retrieved from http://www.autismhandbook.org/images/5/5d/AutismFactSheet2011.pdf

Stankova, T., \& Trajkovski, V. (2010). Attitudes and opinions of employers, ermployees, and parents about the employment of people with autism in the republic of Macedonia. Journal of Special Education \& Rehabilitation,(3/4), 16-29. Retrieved from http://jser.fzf.ukim.edu.mk

Stuckey, W. (2016). Competitive employment and autism spectrum disorder: Employer perspectives (Doctoral dissertation). Retrieved from ProQuest Dissertations \& Theses Global. (Order No. 10108890).

Unger, D. D. (2002). Employer's attitudes toward persons with disabilities in the workforce: Myths or realities? Focus on Autism and Other Developmental Disabilities, 17, 2-10. doi:10.1177/108835760201700101

U.S. Department of Labor. (2017, December 12). Labor force statistics. Retrieved from https://data.bls.gov

Wehmeyer, M. L. (2011). What is next for the transition and employment supports movement? Journal of Vocational Rehabilitation, 35(3), 153-156. Retrieved from http://www.iospress.nl/journal/journal-of-vocationalrehabilitation 